\title{
Certificação Florestal em Grupo no Brasil
}

\author{
Vanessa Maria Bassoํㅜㄹ Laércio Antônio Gonçalves Jacovine ${ }^{1}$, \\ Ricardo Ribeiro Alves ${ }^{2}$, Sophia Lorena Pinto Vieira ${ }^{1}$, Fabiano Luiz da Silva ${ }^{1}$ \\ ${ }^{1}$ Departamento de Engenharia Florestal, Universidade Federal de Viçosa - UFV \\ ${ }^{2}$ Departamento de Gestão Ambiental, Universidade Federal do Pampa - UNIPAMPA
}

\begin{abstract}
RESUMO
O objetivo do presente trabalho foi verificar o contexto da certificação florestal em grupo no Brasil, analisando as perspectivas para os pequenos proprietários florestais do País. O levantamento foi realizado de acordo com dados do website oficial do Forest Stewardship Council (FSC), que é detentor do padrão ao qual são verificadas as certificação em grupo no Brasil . Verificou-se que existem apenas oito certificações em grupo no País e suas principais não conformidades de adequação estão relacionadas com os requisitos legais. Conclui-se, assim, que são poucos os certificados em grupo, se comparados com a quantidade de pequenos e médios produtores florestais existentes no Brasil, e são várias as dificuldades para que estes se adéquem às exigências do processo de certificação florestal no País.
\end{abstract}

Palavras-chave: FSC, manejo florestal, legislação.

\section{Forest Certification Group in Brazil}

\begin{abstract}
The objective of this study was to assess the situation of forest certification group in Brazil, analyzing the prospects for small forest owners in the country. The survey was conducted in accordance with the data from the official website of the Forest Stewardship Council (FSC), which holds the standard in which forest certification group in Brazil is verified. Results showed that there are only eight group certifications in the country and their suitability for main nonconformities is related to legal requirements. It was concluded that there are few certified groups compared to the amount of small and medium producers in forests in Brazil, and also that there are several difficulties for them to fit the requirements of the forest certification process in the country.
\end{abstract}

Keywords: FSC, forest management, legislation.

\section{INTRODUÇÃO}

O setor florestal vem ganhando maior importância nas últimas décadas. No final de 2007, atingiu 3,5\% do PIB nacional (SBS, 2007), mas em meados de 2008 a crise mundial fez o setor entrar em recessão, através da interrupção e redução dos investimentos pretendidos. Com a recuperação da crise durante o ano de 2010, a projeção para 2011 é voltar aos níveis anteriores e recuperar os projetos de ampliação (Associação..., 2010).

Entretanto, juntamente com o crescimento da produção florestal, tem surgido uma maior preocupação com os aspectos e impactos ambientais 
e sociais destas atividades. Todo esse movimento vem sendo impulsionado pela repercussão de notícias a respeito da destruição de florestas tropicais e os consequentes efeitos sobre o clima global. Segundo Alves et al. (2009a), a discussão em torno das questões ambientais e suas relações com o setor florestal são bem nítidas, principalmente, em função da contínua redução das áreas ocupadas por florestas nativas em várias partes do planeta.

Assim, foi necessário criar mecanismos de mercado, que permitissem rotular produtos originados de florestas manejadas de forma adequada, com atividades que respeitem os aspectos ambientais e sociais e, com isso, premiasse ou reconhecesse os produtores que adotavam este sistema de manejo. Como resposta a esta necessidade do mercado, surgiu a certificação florestal, que é um processo voluntário no qual se atesta publicamente que uma floresta é manejada com garantia de sustentabilidade a longo prazo, conservação dos recursos naturais e desenvolvimento socioeconômico.

Ao buscar uma certificação, as organizações estão lançando mão de um instrumento institucionalizado de diferenciação. Tal fato se deve porque tais firmas objetivam informar e garantir ao consumidor, e às demais partes interessadas, que determinados padrões de desempenho de seu manejo florestal estão sendo atingidos e monitorados (Nardelli \& Griffith, 2003).

À medida que a certificação florestal foi se solidificando como um meio de se verificar que a origem da madeira e dos produtos florestais era de procedência correta, a demanda de produtos certificados começou a crescer. Na década de 1990, vários sistemas de certificação foram criados. Em nível mundial, os principais são: o FSC (Forest Stewardship Council) e o PEFC (Programme for Endorsement of Forest Certification Schemes), representados no Brasil pelo programa Cerflor.

Schlyter et al. (2009) citam que a eficiência ambiental de uma norma é dependente do rigor do padrão e da área certificada. Este último, por sua vez, é dependente da legitimidade política, ou seja, do grau de aceitação do padrão. Em sua pesquisa na Suécia, eles concluíram que o rigor das normas do FSC e o do PEFC são bastante similares.
Contudo, de acordo com Nussbaum (2003), verificou-se que o processo de certificação criava alguns problemas para os pequenos proprietários florestais, principalmente com relação às informações e aos custos. Para amenizar esses problemas, surgiu a certificação em grupo, que tem por objetivo reunir um determinado número de pequenas áreas florestais sob o comando de um único 'administrador' capaz de organizar o processo de certificação, permitindo a cada membro se beneficiar dos mesmos diferenciais de mercado que a certificação individual oferece.

A ideia básica por trás de um esquema de certificação em grupo é que, reunindo um grande número de pequenas áreas num mesmo grupo, cada membro pode se beneficiar das economias de escala, mas sem perder o controle de sua própria floresta e do respectivo manejo (Nussbaum, 2003).

Entende-se que a certificação em grupo pode alavancar um sistema de produção mais sustentável e agregar renda aos pequenos produtores florestais. Para verificar como este processo está evoluindo no Brasil, identificar as dificuldades, assim como sugerir as melhorias a serem implantadas, é necessária a realização de trabalhos que tratem da questão. Desta forma, o objetivo do presente trabalho foi verificar a situação da certificação florestal em grupo no Brasil, analisando as perspectivas para os pequenos proprietários florestais.

\section{MATERIAL E MÉTODOS}

O presente estudo foi desenvolvido a partir de metodologias da pesquisa social, sendo esta caracterizada como uma pesquisa descritiva. Segundo Gil (1995, p. 45),

[...] as pesquisas deste tipo têm como objetivo primordial a descrição de características de determinada população ou fenômeno ou estabelecimento de relações entre variáveis. Algumas pesquisas descritivas vão além da simples identificação da existência de relações entre variáveis, pretendendo determinar a natureza dessa relação.

Desta forma, o estudo procurou estabelecer uma relação entre a adesão à certificação florestal na forma de grupo e as facilidades que este processo pode oferecer aos pequenos e médios proprietários rurais. 
A certificação em grupo reúne pequenas áreas florestais sob o comando de um representante, denominado "administrador do grupo", que além de agregar várias funções será a fonte de informação e o responsável pela organização do processo de certificação. Pode-se dizer também, que, no esquema de grupo, a certificação é mais barata porque, sendo o "administrador do grupo" responsável pelo controle do projeto, o certificador faz a auditoria nele e em apenas alguns integrantes do grupo por vez, não precisando avaliar um por um, como ocorre na certificação individual. Além disso, os requisitos de um processo de certificação, como consultas públicas e relatórios, são feitos de uma só vez e os custos, divididos por todos os integrantes do grupo. $\mathrm{O}$ número de integrantes do grupo não é limitado pela norma, cada grupo define essa quantidade em seus requisitos de grupo, assim como as demais especificações.

Como delineamento para a elaboração do trabalho, utilizou-se a pesquisa bibliográfica e documental. A parte inicial do trabalho foi composta pela revisão bibliográfica como fonte de informações sobre o assunto. Salienta-se que, como relata Gil (1995, p. 71) “[...] esta é desenvolvida a partir de material já elaborado, principalmente de livros e artigos científicos."

O levantamento de dados foi realizado por meio de pesquisa documental, que, de acordo com Gil (2008), se assemelha muito à pesquisa bibliográfica, porém a exploração dos dados consiste de fontes documentais que podem ser documentos de primeira ou segunda mão. Na presente pesquisa, utilizaram-se documentos de primeira mão, ou seja, a análise e verificação foram realizadas por meio de documentos oficiais (relatórios de auditoria principal e monitoramentos) da certificação florestal em grupo das unidades de manejo certificadas no período de 2002 a julho de 2010, pelo sistema FSC. Estes são documentos públicos disponibilizados com o objetivo de dar transparência ao processo de certificação. Neste documento, são descritas as ações desenvolvidas na unidade de manejo para o atendimento de todos os princípios e critérios definidos no padrão e necessários para que se obtenha a certificação.
A análise destes documentos contribuiu no entendimento das principais dificuldades encontradas pelos grupos já certificados, através da verificação de suas não conformidades, que representam o termo utilizado para indicar que, na unidade de manejo florestal (UMF), estão sendo descumpridos alguns requisitos que são prescritos pelo padrão. Quando há um descumprimento destes é aplicada à UMF uma solicitação de ação corretiva para a não conformidade identificada.

É oportuno mencionar que o padrão FSC é composto por 10 princípios: obediência às leis e aos princípios do FSC; direitos e responsabilidades de posse e uso; direitos dos povos indígenas; relações comunitárias e direitos dos trabalhadores; benefícios da floresta; impacto ambiental; plano de manejo; monitoramento e avaliação; manutenção de florestas de alto valor de conservação; e plantações de árvores. Assim sendo, essa pesquisa permitiu também verificar quais destes princípios são mais críticos para a adequação ao processo de certificação dos grupos brasileiros já certificados.

Em cada relatório analisado, foram verificadas todas as não conformidades apresentadas pelas organizações florestais certificadas em grupo e, assim, feitas análises do processo, verificando quais as principais exigências com maior dificuldade de adequação. Essas não conformidades foram quantificadas e, desta forma, identificaram-se os princípios mais críticos, possibilitando a comparação com outros estudos. O intuito foi caracterizar as principais dificuldades destas organizações e verificar se estes requisitos já são exigidos por algum tipo de legislação nacional ou são exclusivos do padrão, e dar dimensionamento aos novos processos no País.

\section{RESULTADOS E DISCUSSÃO}

Após 15 anos do início da certificação florestal no Brasil, observa-se que a maior parte dos grandes empreendimentos do setor já passaram pelo processo, principalmente aqueles que praticam o manejo de plantações florestais.

São atualmente, 72 certificados de manejo florestal pelo sistema FSC, correspondendo a uma área de 6.186.73,0 ha (Forest..., 2010). Destes, 
apenas oito são certificações em grupo (Tabela 1), correspondendo a $11,1 \%$ do total.

Em termos do número de certificados, verificou-se que o percentual em grupo é baixo $(11,1 \%)$ quando comparado ao total. Entretanto, ao analisar a proporção em área, o percentual aumenta significativamente, passando para mais de $25 \%$ do total certificado no País.

Esse grande percentual é devido a uma extensa área certificada no Estado do Mato Grosso (Grupo 7), que representa mais de $97 \%$ do total da área certificada em grupo e é composto por 34 integrantes ou manejadores. O restante é composto pela junção de pequenas propriedades, como se verifica na Tabela 1.

Observa-se, também, pelas informações indicadas na Tabela 1 , que sete, dos oito certificados em grupo do Brasil, são referentes ao manejo de florestas nativas. São pequenas comunidades que se juntaram para certificar suas florestas e, consequentemente, seus produtos.

Complementando, tem-se que três destes Grupos (3, 6 e 7) trabalham apenas com produtos não madeireiros, como frutas, sementes e extrativos. Outros três Grupos (2, 4 e 5) trabalham unicamente com produtos madeireiros, ou seja, comercializam toras de madeira nativa, de diversas espécies, porém certificadas. E o Grupo 1 realiza o manejo de forma a comercializar os dois tipos de produtos, os madeireiros e os não madeireiros.

Um ponto relevante, a ser mencionado sobre esse tipo de certificação em grupo, é que a primeira certificação nessa categoria ocorreu em 2002, no
Estado do Acre, a qual está certificada até hoje (Grupo 2). É uma comunidade de produtores e moradores do projeto de assentamento agroextrativistas Chico Mendes.

Segundo Imperador (2009), nos últimos anos, os esforços em promover a certificação comunitária como ferramenta para o desenvolvimento das populações rurais enfatizou a exploração de Produtos Florestais Não Madeireiros (PFNMs). Fato esse que tornou possível a geração de benefícios, como também o surgimento de inúmeros desafios, inclusive o de conciliar as normas de certificação às práticas tradicionais de manejo.

Verifica-se, também na Tabela 1, que há apenas um certificado de plantações florestais em grupo no País. Esta é uma associação de produtores localizados no Estado do Paraná. As propriedades são áreas de fomento florestal de uma grande empresa privada do setor florestal no Estado, que também possui o certificado de suas áreas próprias.

Para Imperador (2009), a estratégia de certificação em grupo adotada pelo FSC teve como objetivo facilitar a certificação florestal de pequenos produtores florestais, sendo considerada uma ótima estratégia, pois contribui e facilita a acessibilidade à certificação, compartilhando custos e habilidades em manejar a produção. Além disso, a união de grupos em cooperativas e associações pode promover maior poder de negociação em relação aos preços e condições de venda de seus produtos. Porém, isto não tem ocorrido no setor florestal aqui no Brasil, pois o número de certificados de pequenos e médios

Tabela 1. Grupos certificados pelo FSC no Brasil, com as respectivas áreas, o Estado e o tipo de floresta.

Table 1. Groups certified by the FSC in Brazil, with their respective areas, the state and type of forest.

\begin{tabular}{cccccc|}
\hline Grupo & Estado & Tipo & Ano & Integrantes & Área (ha) \\
\hline 1 & AC & Nativa & 2004 & 10 & $3.529,00$ \\
\hline 2 & AC & Nativa & 2002 & 50 & $4.390,00$ \\
\hline 3 & PA & Nativa & 2007 & 29 & $4.000,00$ \\
\hline 4 & AC & Nativa & 2005 & 23 & $4.300,00$ \\
\hline 5 & AC & Nativa & 2002 & 12 & $7.468,31$ \\
\hline 6 & AP & Nativa & 2004 & 32 & $2.530,00$ \\
\hline 7 & MT & Nativa & 2006 & 34 & $1.543 .460,00$ \\
\hline 8 & PR & Plantações & 2006 & 10 & $10.957,00$ \\
\hline Total & & & & & $1.580 .634,31$ \\
\hline
\end{tabular}


produtores ainda é baixo para o potencial que o setor apresenta.

Um dos possíveis entraves para o desenvolvimento do processo de certificação são os altos investimentos para adequação das propriedades. Os custos da certificação podem ser divididos em dois: diretos e indiretos. Os diretos são o custo da auditoria e do processo de certificação, enquanto os indiretos são os relacionados a melhorar o manejo e adequar as propriedades para atender às normas FSC. Geralmente, os custos indiretos são maiores que os diretos, pois a adequação aos requisitos da certificação exige vários investimentos financeiros e de tempo dos profissionais da organização.

Basso (2009), por sua vez, comenta que, mesmo nas organizações já certificadas, foram verificadas não conformidades quanto à adequação de suas propriedades e técnicas de manejo, que tiveram que ser resolvidas durante o processo para a manutenção do selo.

Um problema agravante, também, é a falta de informação e desconhecimento por parte dos pequenos e médios proprietários florestais. Na região norte, Organizações Não Governamentais (ONGs) ambientais têm ajudado estas comunidades a se certificarem, levando informações e treinamentos, aos poucos grupos que aderiram a esse processo.

Conforme Alves et al. (2009b), até mesmo os consumidores não têm conhecimento do tema certificação florestal. Esses autores constataram que, embora pouco mais que $40 \%$ dos consumidores entrevistados tenham dito saber o que significa a certificação florestal, somente alguns consumidores realmente reconheceram os selos FSC ou Cerflor, quando estes lhes foram mostrados.

O padrão FSC é composto por dez princípios, que procuram verificar se todas as áreas de atuação do manejo florestal (social, ambiental, legal e econômica) estão de acordo com os padrões de desempenho estabelecidos.

Além deles, a organização que deseja se certificar em grupo deve atender aos requisitos específicos para grupos, que estão diretamente ligados à política do grupo, a procedimentos e responsabilidades da entidade, como: o estabelecimento de regras de adesão e desligamento de membros, definição das obrigações de cada associado, descrição clara de como serão realizadas as ações corretivas, processos de monitoramento das atividades, entre outras coisas.

Por meio dos relatórios de avaliação principal e monitoramento, foi possível quantificar e analisar as não conformidades emitidas pelos órgãos certificadores aos grupos certificados, encontrandose um total de 280 não conformidades. Destas, a maioria foi referente aos princípios $1,4,6$ e às questões referentes aos requisitos de grupo, como demonstrado pela Tabela 2. Juntos, estes somaram $61,7 \%$ do total de não conformidades encontradas.

Esses três princípios estão diretamente ligados ao atendimento das questões ambientais e sociais, sendo eles: obediência às leis e aos princípios do FSC, relações comunitárias e direitos dos trabalhadores e impacto ambiental.

Salienta-se que não foi encontrada nenhuma não conformidade referente ao Princípio 10 (plantações), fato este devido à maioria dos grupos trabalharem com o manejo de florestas nativas. Assim, este princípio não foi evidenciado na Tabela 2.

Todos os grupos certificados apresentaram problemas referentes aos princípios 1 e 4, principalmente, porque estes estão ligados às leis e às condições de trabalho que as propriedades devem atender. Sabe-se que, no Brasil, há uma dificuldade em se atender à legislação ambiental e trabalhista, devido à sua maior complexidade e especificações.

Tabela 2. Porcentagem de não conformidades encontradas nos grupos certificados divididas por princípio do padrão FSC.

Table 2. Percentage of non conformance found in the groups certificates divided by of FSC principle.

\begin{tabular}{|cc|}
\hline Princípio & Não conformidade (\%) \\
\hline 1 & 21 \\
2 & 4 \\
3 & 1 \\
4 & 20 \\
5 & 6 \\
6 & 14 \\
\hline 7 & 12 \\
8 & 9 \\
9 & 1 \\
\hline R. G. & 12 \\
\hline Total & $100 \%$ \\
\hline
\end{tabular}

${ }^{*}$ R. G. é referente às não conformidades dos requisitos de grupo. 
As principais não conformidades dos princípios 1,4 e 6 serão apresentadas, de forma a esclarecer porque estes são os princípios mais críticos de serem adequados nas organizações florestais.

\subsection{Não conformidades relacionadas ao Princípio 1 (obediência às leis e aos princípios do FSC)}

As não conformidades relacionadas ao princípio 1 estão descritas a seguir.

\subsubsection{Falta de disponibilização e de esclarecimento das informações referentes ao processo de certificação}

A falta de disponibilização e de esclarecimento das informações referentes ao processo de certificação a todos os membros do grupo é considerada uma falha, pois todos devem ter informações para que estes possam acompanhar o processo e corrigir possíveis não conformidades em suas propriedades. Esta falta de conhecimento foi a causa de algumas das não conformidades, justamente pelo membro não saber o que deve ser adequado em sua área de manejo. Segundo a certificação em grupo, a obrigação de informar e orientar os manejadores, sobre como devem ser realizadas as atividades, é do administrador.

Verificou-se, nos casos analisados, que o manejador nem sempre está preparado para receber todas as informações e se atualizar constantemente. Além disso, existe um despreparo dos integrantes do grupo, o que dificulta a passagem de informações. Estes estavam acostumados a realizar suas atividades de um modo e, para a certificação, houve a necessidade de se adequarem aos métodos corretos do manejo. Isto tem acontecido de forma gradual e contínua, conforme se verificou nos relatórios, de forma que eles estão se reeducando para garantir a sustentabilidade da floresta.

\subsubsection{Falta do termo de compromisso aos Princípios e Critérios do FSC}

Um dos critérios do princípio 1 do padrão FSC é o compromisso da organização frente à continuidade do manejo e ao atendimento de seus princípios e critérios. Com isso, há a exigência de um documento assinado pelos responsáveis que garanta esses requisitos. Desta forma, a falta de um documento com a assinatura de todos os participantes do grupo, assumindo a responsabilidade e garantia da continuidade do manejo e de suas atividades por um longo prazo, é considerada uma não conformidade.

Verificou-se que sete, dos oito grupos analisados, apresentaram não conformidade neste item, o que comprova falta de informações dos integrantes do grupo. O compromisso tem que partir de todos os manejadores, pois o escopo certificado contempla todas as propriedades, e uma falha em uma das localidades refere-se a um problema na unidade de manejo.

\subsubsection{Falta da garantia e de monitoramento do cumprimento da legislação trabalhista, principalmente com os trabalhadores terceirizados ou temporários}

Outro problema comum, entre os grupos analisados, foi o descumprimento da legislação trabalhista e, na maioria dos casos estudados, as questões estavam diretamente relacionadas aos trabalhadores terceirizados, abrangendo temas como regularização de contratos, recolhimento de encargos e remuneração dentro das normas da CLT (Consolidação das Leis do Trabalho).

De acordo com o texto do padrão do FSC, não é aceitável que a terceirização seja uma forma de flexibilização das relações de trabalho e dos direitos dos trabalhadores. O FSC considera que os princípios e critérios de certificação se aplicam a todos os trabalhadores operando na UMF e prevê que as diferenças de tratamento entre trabalhadores próprios e terceirizados devem ser minimizadas.

Dos sete grupos de manejo de florestas nativas, quatro apresentaram não conformidades com a legislação trabalhista, sendo que mais $80 \%$ destes referem-se aos seus trabalhadores terceirizados, que, normalmente, são contratados por temporada para ajudar no período de colheita. Para a obtenção e manutenção do certificado, foi necessária a regularização destes trabalhadores e o comprometimento do grupo com as normas trabalhistas, conforme relatado nos relatórios analisados. 


\subsubsection{Falta de apresentação do pagamento de taxas e documentos referentes a autorizações do órgão ambiental responsável.}

A falta de apresentação do pagamento de taxas, tais como: licenciamento ambiental (operacional), ATPF (Autorização de Transporte de Produtos Florestais), entre outros, foi uma infração comum entre os relatórios analisados. Grande parte dessas organizações tem dificuldade em se organizar e apresentar os documentos exigidos. Com relação especificamente à ATPF, esse é um problema comum no norte do País. Essa afirmação está embasada nos relatos de Brito \& Barreto (2005). Mais especificamente, esses autores citam que no Pará, em 2005,

“[...] o transporte de madeira sem as Autorizações de Transporte de Produtos Florestais (ATPF) foi a infração mais frequente e o armazenamento de madeira sem autorização a segunda infração mais cometida nos processos verificados"(Brito \& Barreto, 2005, p. 11).

Para se transportar toras de madeira nas estradas nacionais, é necessário ter uma autorização do órgão ambiental estadual (ATPF), com o volume especificado, de que houve autorização para retirada desta madeira da floresta nativa. Esse documento é a comprovação de que a madeira transportada não é oriunda de desmatamentos ilegais.

\subsubsection{Presença de atividades exploratórias dentro das áreas de preservação permanente}

Cada membro do grupo tem que dar garantias do cumprimento da legislação como um todo. Uma infração grave foi a derrubada de árvores dentro das Áreas de Preservação Permanente (APP) sem autorização do órgão ambiental. Pelo código florestal brasileiro, estas áreas devem ser protegidas e qualquer tipo de intervenção, somente mediante a autorização.

Essa infração foi encontrada em apenas um dos grupos, especificamente o Grupo 8, de manejo de plantações florestais. Em umas das localidades, a plantação adentrou a metragem das áreas de preservação permanente e não foi retirada de início. Com isso, no período da colheita foi detectada a infração e, assim, a necessidade de autorização do órgão ambiental para a retirada desta madeira.

\subsection{Não conformidades relacionadas ao Princípio 4 (relações comunitárias e direitos dos trabalhadores)}

As não conformidades relacionadas ao princípio 4 estão descritas a seguir.

\subsubsection{Descumprimento dos requisitos e normas de Saúde e Segurança do Trabalho, principalmente requisitos da NR-31}

As Normas Regulamentadoras - NR, relativas à segurança e medicina do trabalho, são de observância obrigatória pelas empresas privadas e públicas e pelos órgãos públicos da administração direta e indireta, que possuam empregados regidos pela Consolidação das Leis do Trabalho. São 33 normas, criadas em 1978, que regulamentam e fornecem orientações sobre procedimentos obrigatórios relacionados à segurança e medicina do trabalho em seus diferentes tipos de ambientes de trabalho.

A NR 31 - "Norma Regulamentadora de Segurança e Saúde no Trabalho na Agricultura, Pecuária, Silvicultura, Exploração florestal e Aquicultura" é a principal norma de saúde e segurança aplicável ao setor florestal e o não atendimento de seus requisitos na íntegra foi a principal causa das não conformidades levantadas no princípio 4. Foram elas questões relacionadas à falta de equipamentos de segurança, condições de trabalho irregulares, alimentação inadequada, ausência de um local específico para armazenamento de produtos químicos (agrotóxicos) e combustíveis, entre outros.

Todos os grupos analisados apresentaram alguma não conformidade referente a esta norma. Apesar de ser a principal norma de segurança a ser cumprida pelo setor, muitos dos pequenos proprietários ainda a desconhecem, conforme observado nos relatórios analisados. Além disso, esta norma é extremamente complexa, são 23 itens a serem cumpridos, abrangendo vários aspectos e atividades do manejo. Mesmo nas organizações mais estruturadas, foi constatado não conformidades neste item.

\subsubsection{Problemas específicos da atividade de colheita}

Nos procedimentos da colheita florestal ocorreram algumas não conformidades, tais como: a utilização errônea das metodologias de 
trabalho, ausência de sinalização nas áreas e falta de equipamentos de segurança. Para os pequenos e médios proprietários florestais, normalmente utilizase o chamado corte semimecanizado, realizado com motosserras. Como a motosserra é manuseada diretamente pelo operador e a parte cortante fica próxima dele, há um grande risco de acidentes.

Para se evitar acidentes nesta área, o treinamento e capacitação dos operadores de motosserra e seus ajudantes é fundamental. A maioria dos acidentes acontece, normalmente, por falta de cuidado dos trabalhadores. Sobre este tópico, Canto et. al (2007, p. 518) informa que

[...] a atribuição dos acidentes à fatalidade é justificada pelo desconhecimento ou conhecimento parcial dos trabalhadores quanto aos riscos inerentes às atividades de colheita florestal, pois pode afirmar que nenhum acidente ocorre por fatalidade. Os acidentes são causados por atos inseguros, condições inseguras ou os dois fatores em conjunto.

Nos relatórios analisados não foi constatado o relato de nenhum acidente, mas sim evidências de potenciais riscos causadores de acidentes. Em todos os grupos, cuja atividade era madeireira, foram verificadas não conformidades referentes a este item.

\subsubsection{Ausência da elaboração do PPRA \\ (Programa de Prevenção de riscos \\ Ambientais) e do PCMSO (Programa de Controle Médico de Saúde Ocupacional)}

Todos os empreendimentos devem apresentar PPRA e PCMSO, mas poucos proprietários florestais têm conhecimento dessas normas. Essas fazem parte do grupo de normas de saúde e segurança nacionais. Estes são documentos que devem ser elaborados para cada atividade e pode-se contratar uma empresa terceirizada para realizá-los.

Em alguns dos grupos, foi verificada a ausência da elaboração de um desses procedimentos, que são importantes para as atividades florestais. Estes procedimentos foram realizados de forma a contemplar o grupo todo e o administrador ficou responsável pela organização e confecção dos programas. Mas, também é necessário o conhecimento dessas exigências por cada manejador e isto não estava sendo observado, conforme os relatórios analisados.

\subsubsection{Falta de monitoramento das atividades e dos trabalhadores}

O monitoramento das atividades tem o intuito de garantir o cumprimento das legislações, normas trabalhistas e evitar possíveis acidentes de trabalho. Este foi outro requisito de complexa adequação, pois, como se trata de certificação em grupo, tornase mais difícil monitorar todas as atividades em todas as propriedades. Daí a importância de se orientar cada um dos integrantes do grupo para que o monitoramento seja realizado amplamente entre eles.

Esta dificuldade também está relacionada à primeira questão relatada neste trabalho, que é a falta de informações. Não existia um plano de monitoramento por parte do grupo e isto torna muito difícil para o administrador checar todas as atividades no momento em que estas estão ocorrendo. Assim, a responsabilidade passa a ser do proprietário das áreas e é o que normalmente não estava ocorrendo. Alguns dos integrantes dos grupos estavam tendo dificuldade em manter a regularidade de suas atividades dentro das normas.

\subsection{Não conformidades relacionadas ao Princípio 6 (impactos ambientais)}

As não conformidades relacionadas ao princípio 6 estão descritas a seguir.

\subsubsection{Ausência de controle e falta de informações referentes à conversão de área}

A conversão florestal é um problema frequente entre os grupos analisados, principalmente na região Norte, onde grande parte das propriedades é recoberta por mata nativa. De acordo com o Código Florestal, $80 \%$ das propriedades localizadas na região amazônica devem ser mantidas como reserva legal, assim, os produtores devem manter as exigências legais. Mas, os outros $20 \%$, excluindo áreas de preservação permanente, podem ser convertidos para outras atividades, principalmente para subsistência. $\mathrm{O}$ manejo florestal pode ocorrer nas áreas de reserva legal, desde que corretamente realizado.

Mas, a dificuldade estava em repassar corretamente a cada membro do grupo qual 
percentual da propriedade este poderia utilizar para outras finalidades. Todos os grupos de manejo de florestas nativas apresentaram problemas neste item.

Já no Sudeste, as áreas de reserva legal são menores (20\% do total da propriedade) e devem ser respeitadas também. Outro ponto a ser analisado é que, além disso, o produtor tem que respeitar também o ano de conversão para o plantio florestal. Para a certificação FSC, nenhuma área manejada pode ter sido desmatada após 1994. No único grupo de plantações florestais, não houve problema neste item.

\subsubsection{Falta de listagem e definição dos possíveis impactos ambientais que cada atividade florestal pode ocasionar na propriedade}

De acordo com o princípio 6, todos os possíveis impactos causados pelas atividades florestais devem ser listados e medidas para minimizar os impactos negativos e maximizar os positivos devem ser implementadas nas propriedades.

Em pequenas propriedades não é necessário um documento que comprove isso, mas sim a verificação dos cuidados que o proprietário tem antes e após as atividades que possam diminuir os impactos. Às vezes, a vivência mostra muito mais do que procedimentos operacionais.

Quatro, dos oito grupos, apresentaram não conformidades neste quesito, sendo que a maior dificuldade para os integrantes dos grupos é entender como funciona exatamente este monitoramento.

\subsubsection{Falta de um plano de recolhimento e separação do lixo gerado nas propriedades}

Outra questão importante no princípio 6 é quanto ao controle do descarte de resíduos. Cada resíduo tem uma forma correta de destinação para que não agrida o meio ambiente. No caso de propriedades rurais, o lixo doméstico torna-se um problema já que não há recolhimento, assim deve ser separado, e os que têm recolhimento, enviados ao local correto. Tais como: embalagens de agrotóxicos, tambores de combustíveis, pilhas e baterias, lâmpadas, entre outros.

Nos grupos de florestas nativas, cinco apresentaram problemas com a destinação do lixo em suas propriedades, principalmente com os resíduos de pilhas e baterias.

\subsubsection{Falta de um sistema de monitoramento para a fauna silvestre}

É importante um monitoramento da fauna para evitar possíveis atividades ilegais, como a pesca e caça predatória. Assim, como a avaliação dos impactos das atividades florestais, em pequenas propriedades, o monitoramento da fauna pode ser avaliado de acordo com as observações do proprietário. Sendo certificações em grupo, uma avaliação mediante a área correspondente a todos os membros pode ajudar no controle contra as atividades ilegais.

Dois dos grupos analisados apresentaram problemas neste item. Não houve nem mesmo relato sobre os animais presentes na área, sendo considerado um desafio a ser resolvido pelos integrantes do grupo.

\subsubsection{Danos maiores que o necessário nas atividades de colheita (manejo de florestas nativas).}

Danos tais como: abertura de pátios maiores que o necessário, arraste das toras sem controle nas trilhas em meio à floresta, falta de treinamento dos operadores das máquinas utilizadas, entre outros, foram algumas das não conformidades verificadas. Quatro dos grupos certificados de manejo de florestas nativas apresentaram não conformidades em suas atividades de colheita, sendo que a falta de um planejamento das atividades florestais é uma das causas de danos como estes.

Todas as não conformidades identificadas, nos casos estudados, foram devidamente resolvidas pelas organizações estudadas e os relatórios indicam que os aspectos foram monitorados nas auditorias subsequentes. Desta forma, houve um processo de melhoria do manejo das propriedades ao passarem a cumprir os requisitos da certificação.

\subsection{Perspectivas para a certificação em grupo no Brasil}

Como verificado, o número de certificados em grupo ainda é baixo frente ao potencial que o setor apresenta no País, principalmente, para plantações florestais. 
A maior parte das grandes organizações com plantações florestais do setor, atualmente, já possui suas áreas próprias certificadas, mas estão investindo nos programas de fomento como parte de suas estratégias de ampliação. Esses fomentados não são certificados, mas se a quantidade de madeira fornecida representar um maior percentual, como previsto pelas próprias organizações do setor, a certificação florestal será necessária.

$\mathrm{Na}$ última década, o fomento florestal vem atraindo os proprietários rurais, pois, como na maior parte dos casos, as indústrias de base florestal custeiam a implantação das plantações na propriedade, este passa a representar uma boa alternativa para a falta de capitalização do pequeno e médio produtor rural.

Segundos dados do relatório da Associação Brasileira de Produtores de Florestas Plantadas (2010), o Brasil possui mais de 27 mil contratos de fomento florestal formalizados, totalizando uma área de 457 mil ha. A expectativa do setor florestal privado é que até 2012, a área de fomento represente $20 \%$ do total de sua produção.

Dos 72 certificados de manejo florestal, apenas quatro são certificações referentes às propriedades de fomento, sendo uma com certificado em grupo e outras três áreas certificadas nos moldes individuais, localizadas no sul da Bahia. Somadas, essas áreas representam menos de $4 \%$ da área total do fomento no Brasil.

Os custos de adequação das propriedades ao processo de certificação florestal é o maior desafio a esses produtores, mas a certificação em grupo pode trazer uma alternativa a esses fomentados, uma vez que associados possam conseguir melhores oportunidades de negociação. Entende-se assim, que existem dificuldades a serem identificadas para o estabelecimento de planos e, consequentemente, a certificação destas áreas.

\section{CONCLUSÕES}

De acordo com os resultados, pode-se chegar às seguintes conclusões:

- Há apenas oitos grupos certificados no Brasil, representando uma pequena quantidade quando comparados ao total da certificação no País;
- As principais dificuldades para os pequenos e médios produtores florestais se adequarem às exigências da certificação são os requisitos legais (ambientais e trabalhistas);

- O manejador tem dificuldade para manter o cumprimento dos requisitos da certificação por todos os integrantes do grupo, gerando não conformidade que compromete o manejo em geral; e

- Mesmo com as dificuldades apresentadas no trabalho e as não conformidades geradas, acreditasse que a certificação em grupo é a alternativa mais viável para os pequenos e médio produtores florestais que desejarem a certificação florestal de suas áreas.

\section{STATUS DA SUBMISSÃO}

Recebido: $17 / 12 / 2010$

Aceito: 19/06/2011

Resumo publicado online: 25/06/2011

Artigo completo publicado: 30/06/2011

\section{AUTOR(ES) PARA CORRESPONDÊNCIA}

\section{Vanessa Maria Basso}

Pós-graduação em Ciência Florestal, Departamento de Engenharia Florestal, Universidade Federal de Viçosa - UFV, Campus Universitário, CEP 36570-000 e-mail: nessabasso@yahoo.com.br

\section{REFERENNCIAS}

Associação Brasileira de Produtores de Florestas Plantadas - ABRAF. Anuário estatístico da ABRAF 2010: ano base 2009. Brasília: ABRAF; 2010.

Alves RR, Jacovine LAG, Silva ML A, Valverde SR, Silva JC, Nardelli AMB. Certificação florestal e o mercado moveleiro nacional. Revista Árvore 2009a; 33(3):583-589. http://dx.doi.org/10.1590/S010067622009000300020

Alves RR, Jacovine LAG, Pires VAV, Cyrillo FS, Albino AA. Certificação Florestal e o consumidor final: um estudo no pólo moveleiro de Ubá, MG. Revista Floresta e Ambiente 2009b; 16(2):40-48.

Basso VB. Avaliação da contribuição social e ambiental da certificação florestal no estado de Minas Gerais [Monografia] Viçosa: Universidade Federal de Viçosa, 2009. 
Brito B, Barreto P. Aplicação da Lei de Crimes Ambientais pela Justiça Federal no Setor Florestal do Pará. Revista de Direito Ambiental 2005; 37. p. 11.

Canto JL, Machado CC, Souza AP, Garlet A, Carvalho RMMA, Noce R. Avaliação das condições de segurança no trabalho na colheita e transporte florestal em propriedades rurais fomentadas no estado do Espírito Santo. Revista Árvore 2007; 31(3):513-520.

Forest Stewardship Council - FSC. Global FSC certificates: type and distribution. FSC; 2010.

Gil AC. Métodos e técnicas de pesquisa social. $4^{\text {th }}$ ed. São Paulo; 1995. 207 p.

Imperador AM. Percepções locais de manejadores comunitários sobre a Certificação do Conselho de Manejo Florestal (FSC) para produtos florestais não madeireiros no estado do Acre [tese]. São Carlos: Universidade Federal de São Carlos; 2009.

Nardelli AMB, Griffith JJ. Modelo teórico para compreensão do ambientalismo empresarial do setor florestal brasileiro. Revista Árvore 20003; 27(6):855-859.

Nussbaum R. Certificação em grupo: um guia prático. Piracicaba; 2003. 58 p.

Schlyter P, Stjernquist I, Bäckstrand K. Not seeing the forest for the trees? The environmental effectiveness of Forest certification in Sweden. Journal Forest Policy and Economics 2009; 1(5-6):375-382. http://dx.doi. org/10.1016/j.forpol.2008.11.005

Sociedade Brasileira de Silvicultura - SBS. Fatos e Números do Brasil Florestal [online]. 2007. [cited 2010 abr. 3]. Available from: http://www.sbs.org.br 